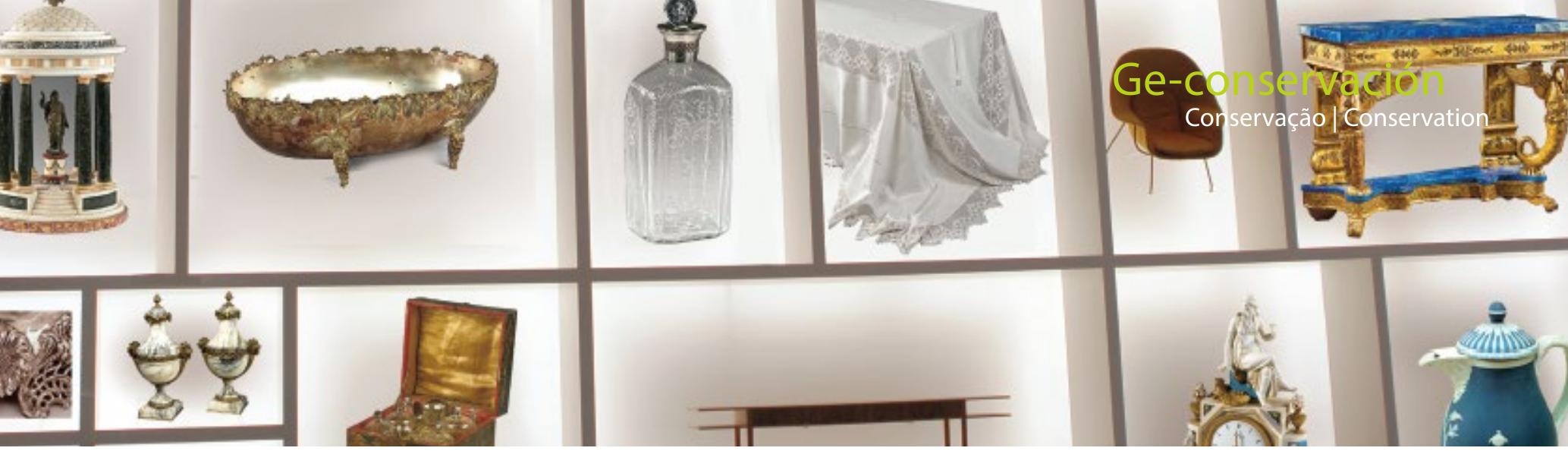

\title{
Industria, decoración y diseño. Historias del Museo Nacional de Artes Decorativas
}

\author{
Paloma Muñoz-Campos y Sofía Rodríguez Bernis
}

\begin{abstract}
Resumen: La posición de las artes decorativas -artes aplicadas, cultura material, diseño, artesanía- en el panorama actual cultural de los museos está necesitada de una reflexión para conectar con la sociedad y con los cambios operados en la museología del siglo XXI. El Museo Nacional de Artes Decorativas (MNAD) ha reflejado en su evolución el desarrollo de las profesiones dedicadas a los objetos de consumo. Aunque en sus inicios como Museo Nacional de Arte Industrial (MNAI) se centró en el fomento de los productos de la segunda Revolución Industrial, acabó por perder la batalla de la modernidad tras la Guerra Civil, privilegiando el acopio de "obras de alto valor decorativo", al margen del debate contemporáneo fuera de nuestras fronteras, que buscaba tender un puente entre arte e industria. Hoy el museo se enfrenta al nuevo reto de prestar servicio a una sociedad en crisis y trabaja en su redefinición conceptual como institución, hacia la construcción de un nuevo museo. Un museo de todos y para todos, que nos ayude a comprender los objetos que configuraron y configuran nuestro entorno.
\end{abstract}

Palabras clave: Artes decorativas; Artes industriales; Diseño; Museografía; Museología; Historia de los museos; Pedagogía de las artes; Museo social

\section{Industry, decoration and design. Tales from the Museo Nacional de Artes Decorativas}

\begin{abstract}
Some consideration is required about the role that decorative arts (applied arts, material culture, design, craft) play in our museums today, in the aim to connect with the society and the museology of the twenty-first century. The National Museum of Decorative Arts (MNAD) reflected along its history the evolving professions related to the range of objects which fills people's lives. Although from its beginning as National Museum of Industrial Arts (MNAI) focused on the encouragement of products from the Second Industrial Revolution, it missed the connection with Modernity after the Civil War. It remained far from the European debate about art and industry, favouring "objects of high decorative value". In the need for serving a society in crisis we face new challenges today. We are working hard to redefine the mission statement of the institution. Our aim is to build a new museum, constructed by everybody and for everyone, which help us to understand the objects that shaped our lives in the past and still do it now.
\end{abstract}

Key words: Decorative Arts; Industrial Arts; Design; Museography; Museology; History of Museums; Art Pedagogy; Social Museum

En primer lugar queremos mostrar nuestro agradecimiento al Grupo de Artes Decorativas del GEIIC por habernos invitado a participar en este encuentro y contribuir así al conocimiento y la difusión de las artes decorativas en nuestro país. Nos centraremos en las etapas de evolución del Museo Nacional de Artes Decorativas (MNAD), que ahora cumple cien años de existencia [figura 1], como muestra del camino que las artes decorativas han recorrido en España desde finales del siglo XIX, momento en el que se empieza a gestar la idea de crear un museo de estas características.
La posición de las artes decorativas en el panorama actual dentro del patrimonio cultural de los museos, ha de ser reconsiderada y sometida a una reflexión que le permita conectar con la sociedad del siglo XXI y adaptarse a los recientes cambios operados en la museología. Esta es una de las tareas en la que está inmerso el MNAD, que trabaja desde hace algunos años en su re-definición conceptual como Institución. Queremos construir un nuevo museo que, además de custodiar tesoros, aporte algo más a una sociedad en crisis en un sentido amplio. Y pensamos que en ello puede residir la clave de su apreciación por parte 
del público, en saber transmitir que lo que en el museo encuentran apela directamente a su entorno cotidiano y en subrayar así su calidad simbólica y material.

El que hoy conocemos con la denominación de Museo Nacional de Artes Decorativas, nació en 1912 como Museo Nacional de Artes Industriales (MNAI). Ello, como veremos, no fue casual, sino que respondía a la intencionalidad de la época. Hoy es nuestra intención, en un futuro cercano, cambiar la denominación del museo para que incluya el concepto de diseño, pues nos parece más acorde con la actual filosofía de nuestra institución'.

Plantearemos cuatro etapas conceptuales en la evolución del museo:

-1912-1927. El Museo Nacional de Artes Industriales.

-1927-1973. El Museo Nacional de Artes (más que nada) Decorativas.

-1973-2003. Un nuevo sesgo profesional.

-De 2003 hasta la actualidad.

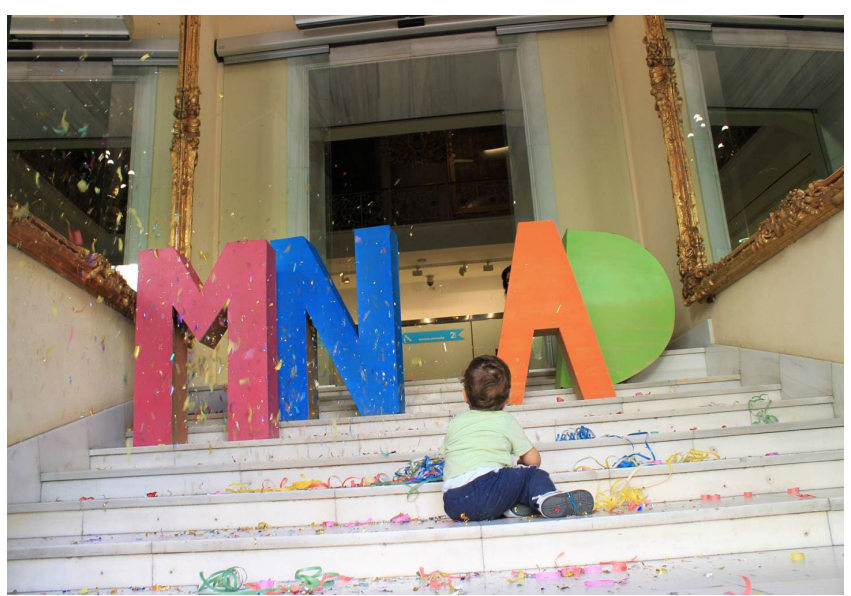

Figura 1.- Escalera de entrada a MNAD en Montalbán 12. $O M N A D$

\section{2-1927. El Museo Nacional de Artes Industriales}

El siglo XX se iniciaba en España con un problema sin resolver: la potenciación de las débiles industrias que fabricaban productos para el consumo. Aquí la mecanización, la organización del trabajo, la formación de los trabajadores y la definición de nuevos criterios estéticos, es decir, los fundamentos de la segunda Revolución Industrial, evolucionaban a la zaga de la Europa industrializada. En los años ochenta del XIX, la iniciativa de los sectores económicos e intelectuales más activos, apoyada en una política arancelaria proteccionista, había logrado mejorar el rendimiento y la calidad del sector de las, por entonces, llamadas "artes

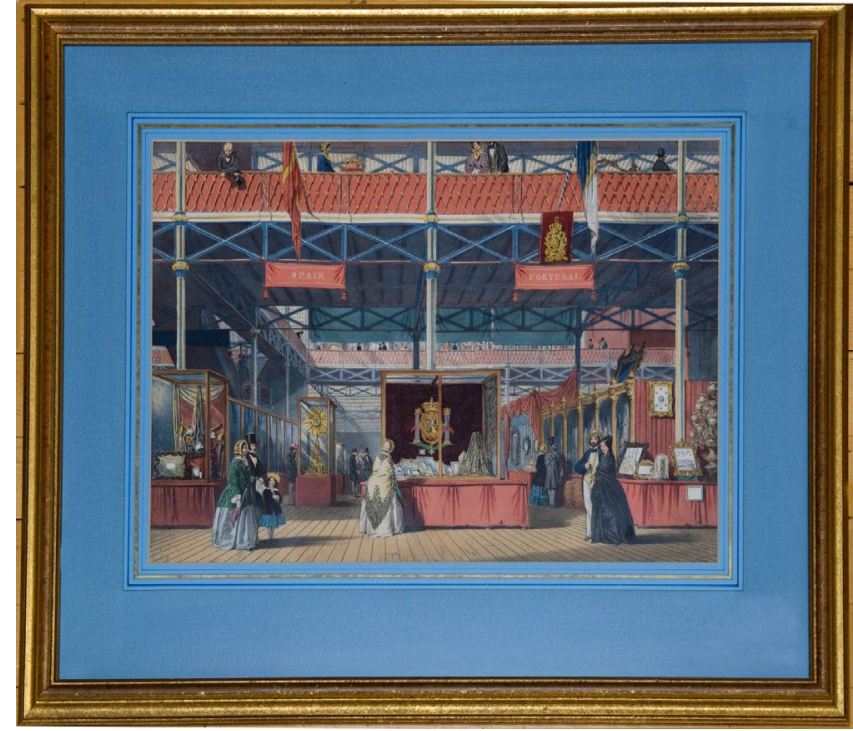

Figura 2.- Secciones de España y Portugal, Dickinson Comprehensive Pictures of the Great Exhibition of 1851 (Londres), estampa iluminada. $\odot M N A D$

industriales". Pero treinta años después, cuando se creó el museo, estas mejoras aún no resultaban suficientes para que nuestro país fuera competitivo.

Los precedentes directos de los museos de artes decorativas son las exposiciones universales, que empezaron a organizarse a mediados del siglo XIX (Londres, 1851) y cuya finalidad era mostrar productos industriales de calidad, junto con los que se exponían objetos del pasado que contribuyeran a servir de inspiración para los artesanos e industriales.

Pero en el mundo de las exposiciones internacionales y universales, nuestro país sólo había destacado por las producciones decorativas y artesanales, fabricadas en series limitadas [figura 2]. El representante más importante de ese moderado éxito español, Eusebio Zuloaga, recibió una primera medalla en la Exposición Universal de 1862. Sus objetos ornamentales, de tipologías tradicionales, fueron ricamente adornados con trabajos de metalurgia en damasquinado. Se trataba del embellecimiento de la modernidad con el vestido de la tradición y es lo que permitió a España hacerse un cierto hueco en la Europa de su tiempo².

Y la fundación del museo está claramente relacionada con esta situación, pues podemos ver cómo el anuario del MNAl de 1916 [figura 3] —el único publicado- se hacía eco de esta preocupación y la relacionaba con la razón de su existencia: "El personal de este museo... hizo un cálculo de lo que aproximadamente importaba España al año en objetos de artes industriales, pasando la cifra obtenida de cincuenta millones de pesetas... Una de las finalidades (del museo), ha de ser la más amplia difusión de sus elementos de cultura en las industrias 


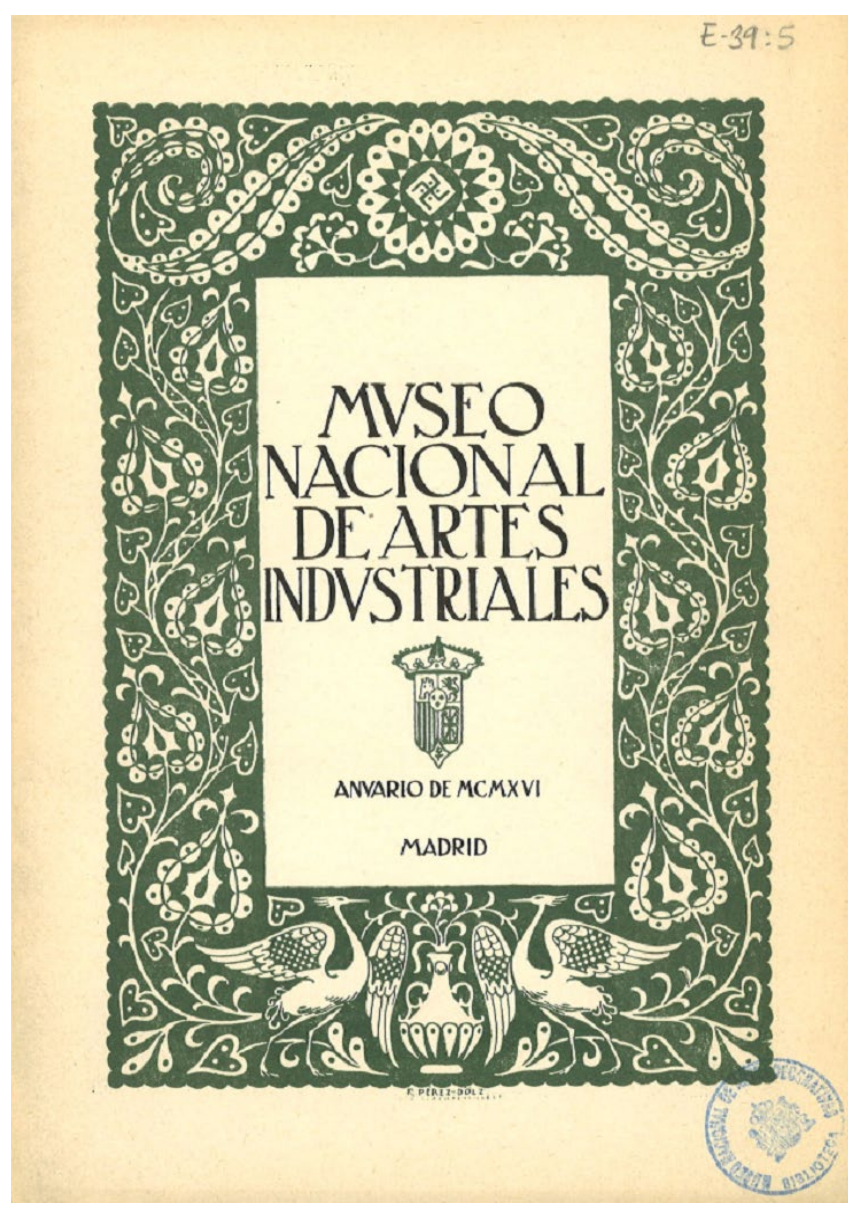

Figura 3.- Portada del Anuario de MCMXVI. @ MNAD

artísticas... disminuyendo la cifra...(que) paga nuestra nación a las extranjeras al comprarles objetos que nosotros no producimos o elaboramos mal" ${ }^{\prime 3}$. Es decir, existía una preocupación por fomentar nuestros productos industriales y dotarlos de calidad, para que pudieran ser competitivos y pudieran disminuirse las importaciones.

Consciente de ese potencial, el Ministerio de Instrucción Pública creó el MNAl, para "atender al fomento de las industrias artísticas españolas", que se encuentran en "competencia ruinosa" con el resto de Europa. En sintonía con lo sucedido en otras naciones como Inglaterra, y en el seno de los movimientos regeneracionistas españoles, se pensaba que sólo a través de la educación se podía transformar sensiblemente a la sociedad. El museo se consideraba un entorno idóneo para educar al adulto [figura 4].

El decreto de fundación, de 30 de diciembre de 1912, explicaba este propósito, que matizaba así: "tendrá como función esencial, no la mera delectación artística y contemplativa, sino el promover la cultura artística y técnica de la artes aplicadas en el público, y especialmente en los artistas, industriales y obreros" ${ }^{\prime \prime}$. Su vocación se planteaba como principalmente pedagógica

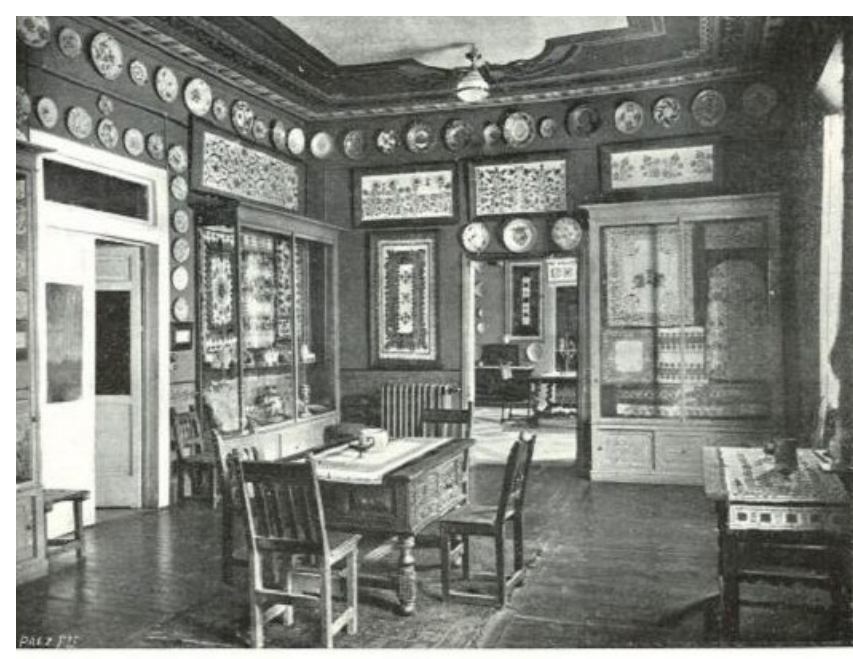

SALA PRTIEBa

Figura 4.- Sala Primera del piso $2^{\circ}$ del núm. 5 de la calle Sacramento. () MNAD

y formativa, siguiendo el modelo establecido sesenta años antes por el South Kensington Museum -hoy Museo Victoria \& Albert-. Cierto es que la intención de constituir un museo de esta tipología existía desde mediados del siglo XIX, aunque no esté claramente documentada, ya que hubo un par de iniciativas fallidas en 1851 y 1871. Para alojar las colecciones, en febrero de 1915 se firma el contrato de arrendamiento de algunas habitaciones del piso segundo del número 5 de la calle Sacramento, que al año siguiente sería ampliado. Las incipientes colecciones ofrecieron al "artista industrial" un modelo matizado por el "buen gusto", si utilizamos la terminología de la época, que estaba más próximo al mundo de las artes que a la estética de la máquina que iba abriéndose camino en otros foros europeos y americanos.

Una de las contribuciones más innovadoras del MNAI fue la recuperación de la cultura popular tradicional, valorada por su simplicidad fundamental, no contaminada por los historicismos decimonónicos, y por la sencillez y enraizamiento local de los procedimientos de fabricación. Se apreciaba doblemente por ser manifestación del amor al trabajo y de las capacidades manuales que fomentaba la pedagogía más avanzada. Los responsables de la etapa inicial de museo compartían estos presupuestos. Los dos primeros directores, Rafael Domenech y Luis Pérez Bueno y el profesor Francisco Pérez Dolz -catedrático de la Escuela de Artes y Oficios de Granada y agregado del Museo -fueron pensionados para estudiar instituciones semejantes en Europa. Es seguro que visitaron Francia e Inglaterra.

Muchas de las piezas fundacionales proceden, precisamente, de la producción "popular", tal y como se interpretaba a principios del siglo XX: camisas bordadas salmantinas, sillas de palos, arcas de diferentes áreas geográficas en las que la decoración encarnaba la 


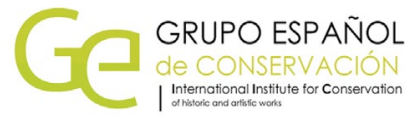

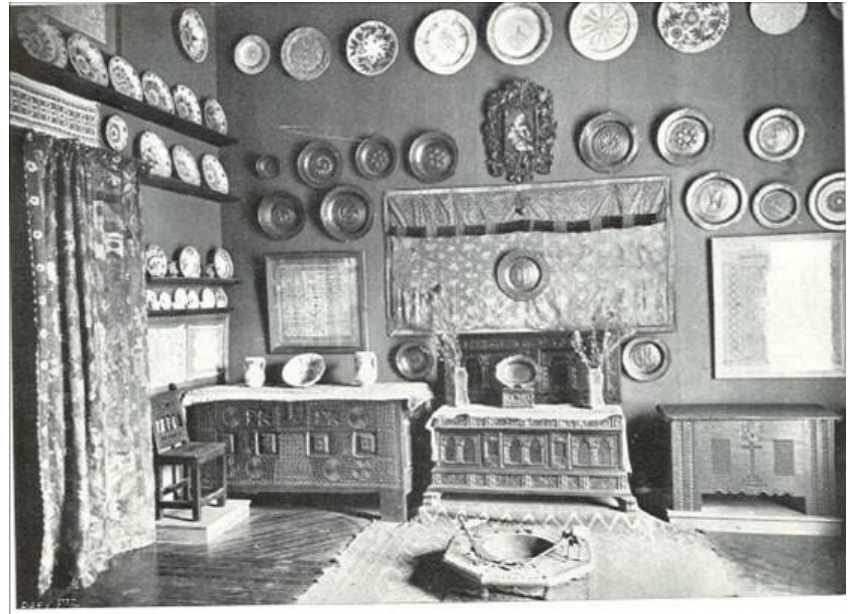

SALA TERCERA

Figura 5.- Sala Tercera del piso $2^{\circ}$ del núm. 5 de la calle Sacramento. $\odot$ MNAD

identidad local o cerámicas de los diferentes alfares españoles. Las piezas populares se expusieron junto a objetos más "cultos" [figura 5]: limosneros de Dinand, colchas indo-portuguesas, antiguas sedas labradas... Esa mixtura de "objetos antiguos y modernos", como decía el real decreto de creación del museo, tenía un claro propósito: enseñar "procedimientos, técnicas, materiales y decoraciones" a los trabajadores de las industrias artísticas. Así que, en este momento, todos los niveles de la producción humana, con independencia de que la erudición los hubiera calificado de "mayores" o "menores" se yuxtapusieron en las salas, sin que ninguno tuviera prioridad sobre el resto. También se reservó una sala para la producción contemporánea.

Las distintas producciones, como podemos reconocer en las imágenes, se muestran en series y formando "habitaciones". Los documentos nos dicen que cada objeto se puso "en una disposición igual o parecida a la que tuvo"s $y$, si eso no era posible, las series de materiales y técnicas, se mostraban combinadas entre sí para evitar "toda la aridez posible de cosa muerta o almacenada". Una incipiente evocación de la función que el objeto tuviera en sus orígenes.
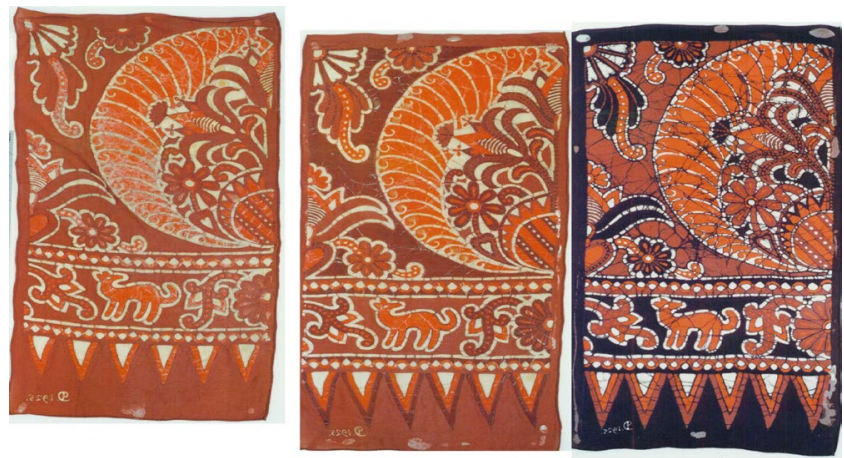

Figura 6.- Ejemplo de proceso de creación de un batik. @ MNAD

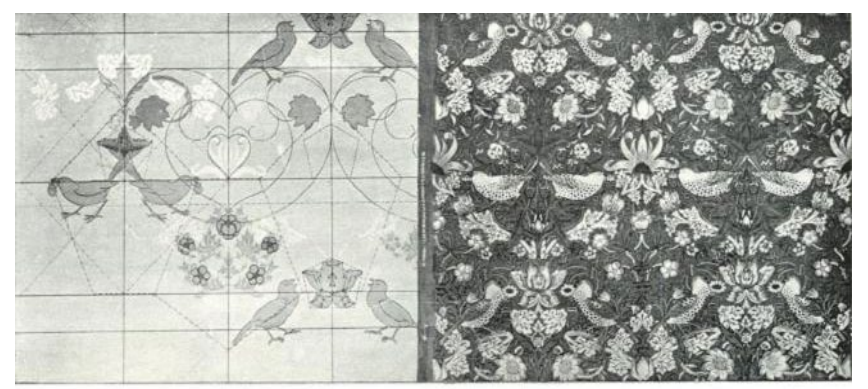

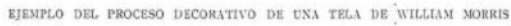

Figura 7.- Ejemplo de proceso decorativo de una tela de Morris. (c) MNAD

El museo era en buena medida un taller educativo, que atendía a las consultas de "artistas, decoradores e industriales" y corregía los proyectos que se le sometían. Sabemos que contó con una sección dedicada a la "pedagogía de las artes industriales", labor en la que el Reglamento de 1913 hacía hincapié. Aunque las actividades están aún poco estudiadas, se sabe que su organización corrió sobre todo a cargo de Pérez Dolz, y que se prepararon "series técnicas" que sirvieran de ejemplo a los artesanos e industriales: esmaltes translúcidos, bordados, batiks, unidades decorativas talladas en madera. Se conservan algunas de ellas, como el proceso de creación de un batik o una tela de Morris montada sobre cartones, con dibujos adyacentes en los que se apuntaban las líneas compositivas [figuras 6 y 7].

Para apoyar la labor educativa, el museo contaría con una biblioteca, dotada con libros, revistas, estampas y fotografías, relacionadas con los fondos museográficos. Se pretendía, además, conseguir un horario de tarde, adecuado a la disponibilidad de los obreros fuera de su jornada de trabajo. Los visitantes, unos cuarenta anuales, firmaban un libro, gracias al cual sabemos que también arquitectos, artistas e investigadores frecuentaban el museo; en él aparecen, entre otras, las rúbricas de Gutiérrez Soto, José María Muguruza, Luis Martínez Feduchi, Sáenz de Tejada, Gregorio Prieto, Benjamín Palencia, Luis Quintanilla, Carmen Baroja y García Bellido.

\section{7-1973 El Museo Nacional de Artes (más que nada) Decorativas}

En 1927 el museo abandonó el camino hacia la industria moderna, del que se había ido apartando progresivamente. En ese año, el Patronato propone al Ministro un nombre nuevo para la institución: Museo Nacional de Artes Decorativas. La justificación del acuerdo, que refleja un cambio de rumbo conceptual sustancial, aduce que la decisión se tomó para que el museo pudiera incluir ...obras de alto valor decorativo que, no siendo de producción industrial, son sin embargo las que en todas las épocas y países han mostrado los 
caracteres artísticos directrices en la producción de las artes industriales... En lo que no existen dudas es en que esas obras son siempre decorativas, pues el término "industrial" es una modalidad del término amplio "decorativo".

Se opta, así, por una acepción restrictiva del término "industrial", que elimina los productos de la máquina que no estuvieran embellecidos por un valor añadido ornamental. De este modo se dio la espalda a las investigaciones de vanguardia que se abrían camino por esos años, como, por ejemplo, a la firma Rolaco (muebles de tubo de acero diseñados por Feduchi), a Sert o a los muebles diseñados por los arquitectos de la Generación del 25.

Tras la Guerra Civil se ahondó en la tendencia a buscar refugio en la decoración. Se convierte en criterio de acopio y en pie forzado para la investigación, sin comprometer al museo en los debates contemporáneos. La producción coetánea quedó definitivamente olvidada, excepto en lo que se refiere a algunas especialidades como el belenismo o algunos diseños textiles.

El pasado se convirtió en protagonista, y sobre todo el pasado nacional, el hogar español recreado a través de las distintas épocas y estilos. En 1941, la Revista Nacional de Educación lo expresaba con claridad: ...El Museo orientará el afán artístico de nuestros artesanos y fomentará la investigación de nuestras artes decorativas..., y proseguía: ...Tras el paréntesis de incuria artística, que trazó la dominación roja en Madrid, ha abierto de nuevo sus puertas, remozado y pujante, el Museo Nacional de Artes Decorativas, que en la maravillosa variedad de sus salas exhibe los valores artísticos de nuestra gloriosa artesanía, revalorizada hoy día por las sabias directrices del Movimiento Nacional... ${ }^{6}$

Tenemos confirmación del cambio de nombre en 1931. En 1932 ó 33 el museo se mudó al edificio de la calle Montalbán en el que aún hoy está instalado ${ }^{7}$. Ya el anuario de 1916 expresaba el deseo de "una instalación más perfecta", que "debería llegar, en muchos casos, a formar habitaciones completas" ${ }^{\prime 8}$. Además, desde su primera década se documentan cartas al Ministro pidiendo más espacio. Antes de la guerra el museo se instala en el palacete de la Duquesa de Santoña, que había sido Escuela de Magisterio y que es definitivamente adquirido por el Estado a los herederos en 1941.

En su nuevo emplazamiento nos vamos a encontrar con una escenografía de ciertas pretensiones aristocráticas [figura 8], como podemos leer en la Revista Nacional de Educación de 1941: ...Tres pisos, cuenta hoy el Museo. En la planta baja se exhiben los distintos tipos de objetos que decoraren nuestros palacios y casas: loza, vidrios, cueros y talla... En el piso principal se ha tendido a presentar habitaciones completas de un solo estilo... Suntuoso el salón dieciochesco... El dormitorio severo y adusto, del

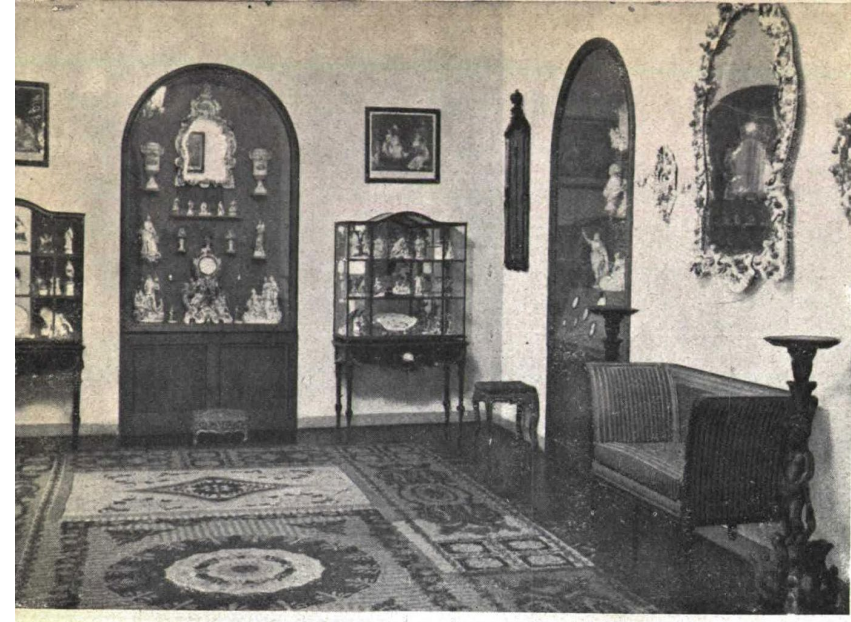

La sala de las porcelanas. Filigranas de Sevres, de Sajonia, del Retiro, en el marco suntuoso de la sala dieciochesca.

Figura 8.- Ejemplo de montaje de salas en la calle Montalbán: sala de las porcelanas. Revista de Educación Nacional, 1941. CMNAD

siglo XVII, tapizado con lienzos de Bruselas..., el comedor señorial, que cobija el magnífico artesonado mudéjar del Palacio de los Condes de Fuensalida en Toledo, y la ventana y chimenea del mismo edificio, de estilo gótico, entonando con la colección de sillones frailunos y una majestuosa mesa central del siglo XVI... ${ }^{9}$

Siendo directora Pilar Fernández Vega, viuda del catedrático José Ferrandis, que había sido Subdirector en la primera década, se acometió la ampliación del edificio entre 1942 y 1944, agregándose dos plantas y un anexo, según el proyecto de Luis Moya Blanco (1942-44). La reinauguración, en 1949 ó 50, mostró una exposición permanente más grande, pero con una museografía muy semejante a la ya descrita: series tipológicas y ambientes.

Las necesidades que planteaba el museo en la década de los sesenta suenan extrañamente parecidas a las actuales: "una publicidad acertada y establecer un horario de tarde". Esas son las razones a las que Lolita Enríquez, sucesora de Pilar Fernández Vega en la Dirección, atribuía el bajo número de visitantes ${ }^{10}, 3.484$ en 1966.

Parece que hubo una nueva intervención, que fue abierta al público en 1972, en la que, además de consolidarse los cimientos, se ganaron una sala de exposiciones en la planta sótano y un almacén en la planta quinta. En la planta tercera se reservaron varias salas a las producciones "populares", que hoy más bien calificaríamos de regionales, diferenciadas por sus "estilos" locales. Y perduraba el contraste con las manufacturas de lujo, organizadas en ambientes historicistas. Manuel Pombo Angulo hace, en el periódico La Vanguardia Española, una lírica descripción del efecto logrado: ...Y el milagro se ha producido. Esta mañana, Doña Carmen Polo de Franco inauguró - sí, porque, en realidad, de una inauguración se trataba- el renacido, o, si se quiere, nacido, Museo 


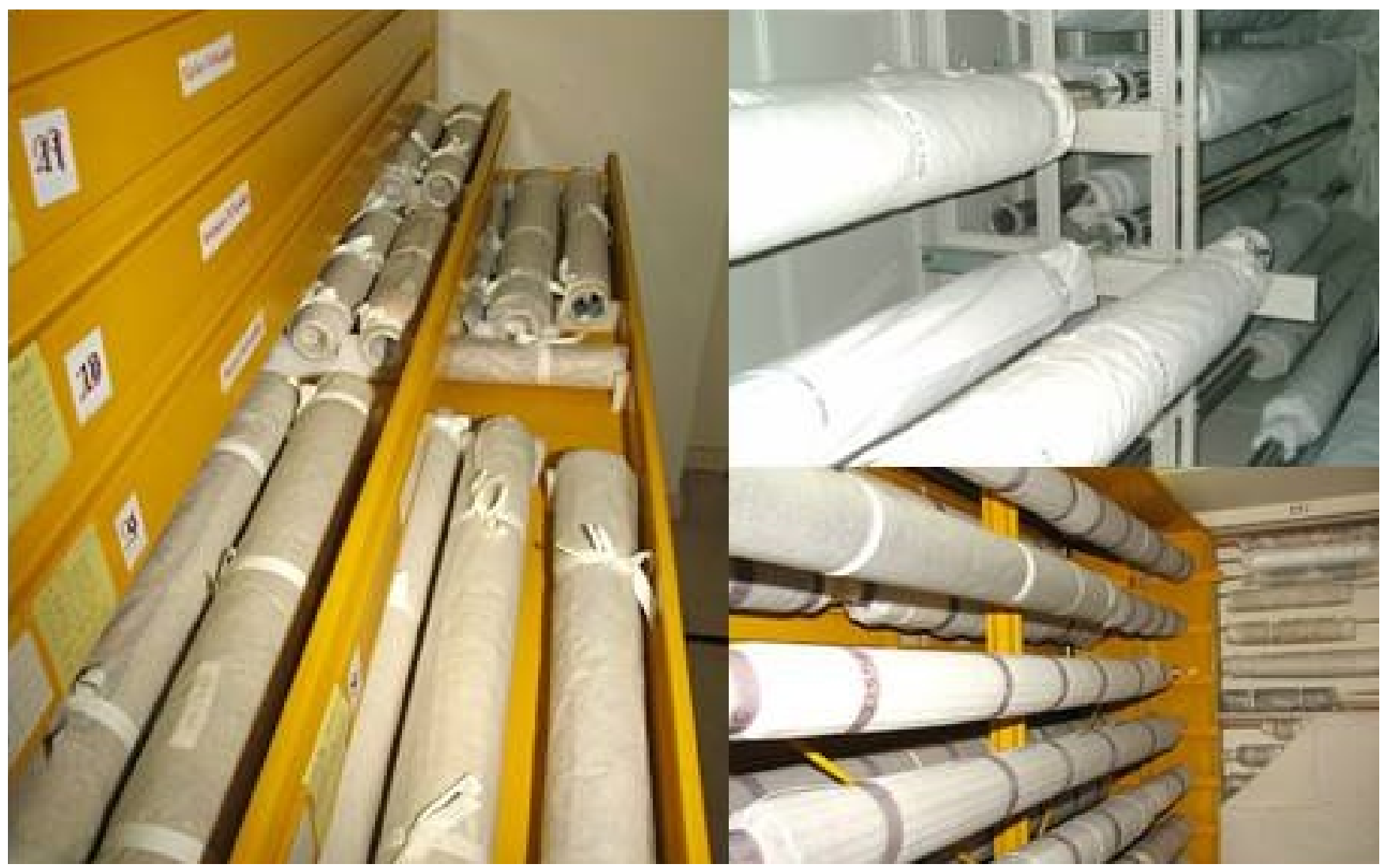

Figura 9.- Almacenes de tejidos a principios de la década de los 90'. $\odot$ MNAD

de Artes Decorativas. Todo es en él ahora como si hubiese despertado de un sueño, en el que los fantasmas hubiesen cobrado vida, materializándose, como en el cuento de los cien años dormidos... un recreo constante para los que, de pronto, se encuentran con este museo, despierto ya de su maleficio, con música en los clavecines, y aire y no pátina en los abanicos... ${ }^{11}$. El enfoque hogareño atrajo a un público fundamentalmente femenino, y el aspecto lujoso y recargado sedujo sobre todo a la burguesía acomodada. Isabel Ceballos sería la tercera directora en esta etapa.

\section{3-2003 Un nuevo sesgo profesional}

Poco a poco el museo se fue dotando de personal procedente de las oposiciones de facultativos de museos. Los nuevos técnicos, junto con los directores Gabriel Moya Valgañón y Alberto Bartolomé Arraiza, introdujeron la estructura de tareas de la museología contemporánea, creando un museo de funciones, del que fue protagonista la documentación como criterio ordenador de la gestión de los fondos museográficos, como sucedió en muchos otros museos entre los años setenta y los noventa. De lo que en la profesión se conoce como "las fichas de Navascués", se pasó a la normalización documental promovida por la SGME, que cristalizaría en el Sistema de Gestión Museográfica DOMUS, a cuyo desarrollo inicial algunos de los miembros de la plantilla contribuyeron activamente.
El museo inició asimismo en la última década del siglo XX la implantación pionera y progresiva de una política de conservación preventiva, que contribuyó a abrir paso en los museos estatales a la figura del conservadorrestaurador y a nivelar la consideración relativa de la conservación-restauración dentro de las funciones del museo. Algo inusitado para aquellos tiempos, que ha creado escuela y ha contribuido al desarrollo de la conservación preventiva como disciplina y a la práctica razonada en muchos de nuestros museos [figura 9].

Algo se avanzó en estos años en la organización de la exposición permanente: en parte del conjunto de las salas se planteó un esbozo de separación física, y por tanto intelectual, entre las piezas y el público [figura 10 y figura 11]. Se formaron conjuntos de fondos museográficos agrupados por estilos, por funciones o por técnicas constructivas y decorativas. Además, en algunas zonas se recurrió a la exposición sistemática, ya existente antes en el museo, pero ahora puesta al día y concebida para expresar aspectos significativos de las formas de producción [figura 12].

La gran novedad de este período fue la incorporación del diseño contemporáneo internacional a las colecciones históricas, gracias a la adquisición, en 1999, de la colección Bröhan, que dibuja una historia de la opción racionalista — aunque hay piezas de otras tendenciasdel diseño industrial del siglo $\mathrm{XX}$, con alguna incursión 


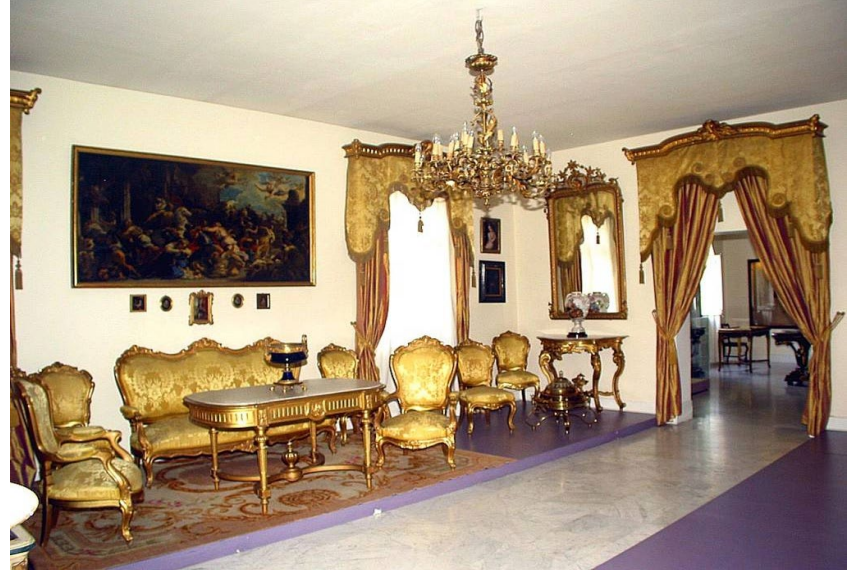

Figura 10.- El llamado "salón amarillo" de la planta cuarta, remodelada en los años 1995-96. @ MNAD

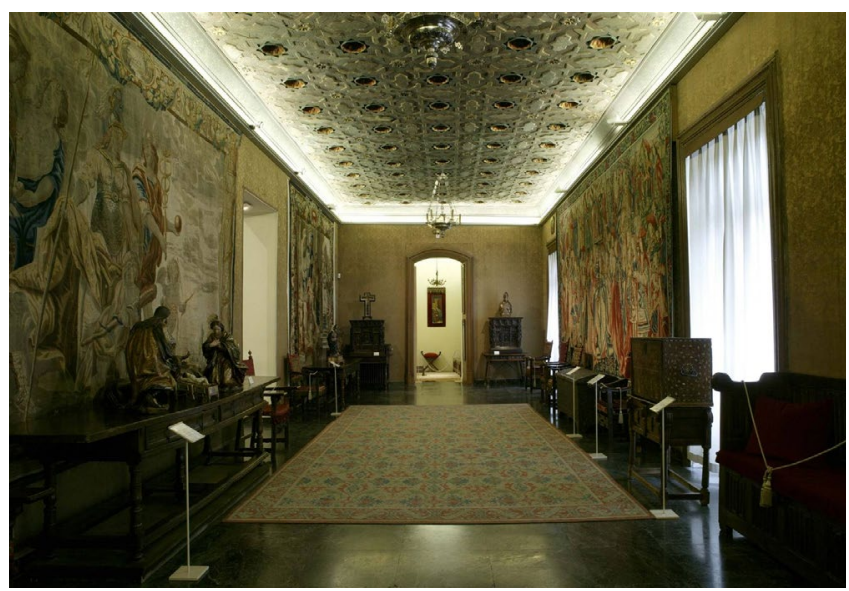

Figura 11.- Sala de la planta primera, llamada "sala de tapices". (c) MNAD en el diseño gráfico y en la indumentaria [figura 13]. Componen este fondo piezas de Frank Lloyd Wright, Alvar Aalto, Josef Hoffmann, Gerrit Rietveld, Mies van der Rohe -entre las que se encuentra un prototipo de la silla Barcelona-, Elsa Schiaparelli y Kandinski, entre muchos otros autores.

\section{De 2003 hasta la actualidad}

A partir de la redacción de nuestro Plan Museológico en 2003, el Museo da otro giro importante, que es el que nos está conduciendo a la actualidad. Tres son los documentos que han sentado las bases para la renovación conceptual cimentada en nuevos objetivos, presididos por la finalidad de contribuir a "diseñar nuestro entorno": El plan museológico (2003) desarrollado en objetivos anuales (2003-2009), el plan bianual (2009-2010) y el plan director (2011).

El primer objetivo es transformar el Museo "de los estilos" en el de la cultura material cotidiana, la de las artes y del diseño, enfocada desde un punto de vista contemporáneo, como instrumento de creación y formación, y como motor económico; pero con el matiz de poner de relieve todo aquello que ha contribuido a crear, ayer y hoy, un entorno vital de calidad, socialmente responsable. Además, el MNAD se ha comprometido con la reinterpretación de sus colecciones, contextualizadas de manera que muestren los valores de producción y de comercialización, creativos, de uso, ideológicos y simbólicos de los objetos. Para ello, el museo desarrolla un conjunto de programas generales, entre los cuales destacan los siguientes:

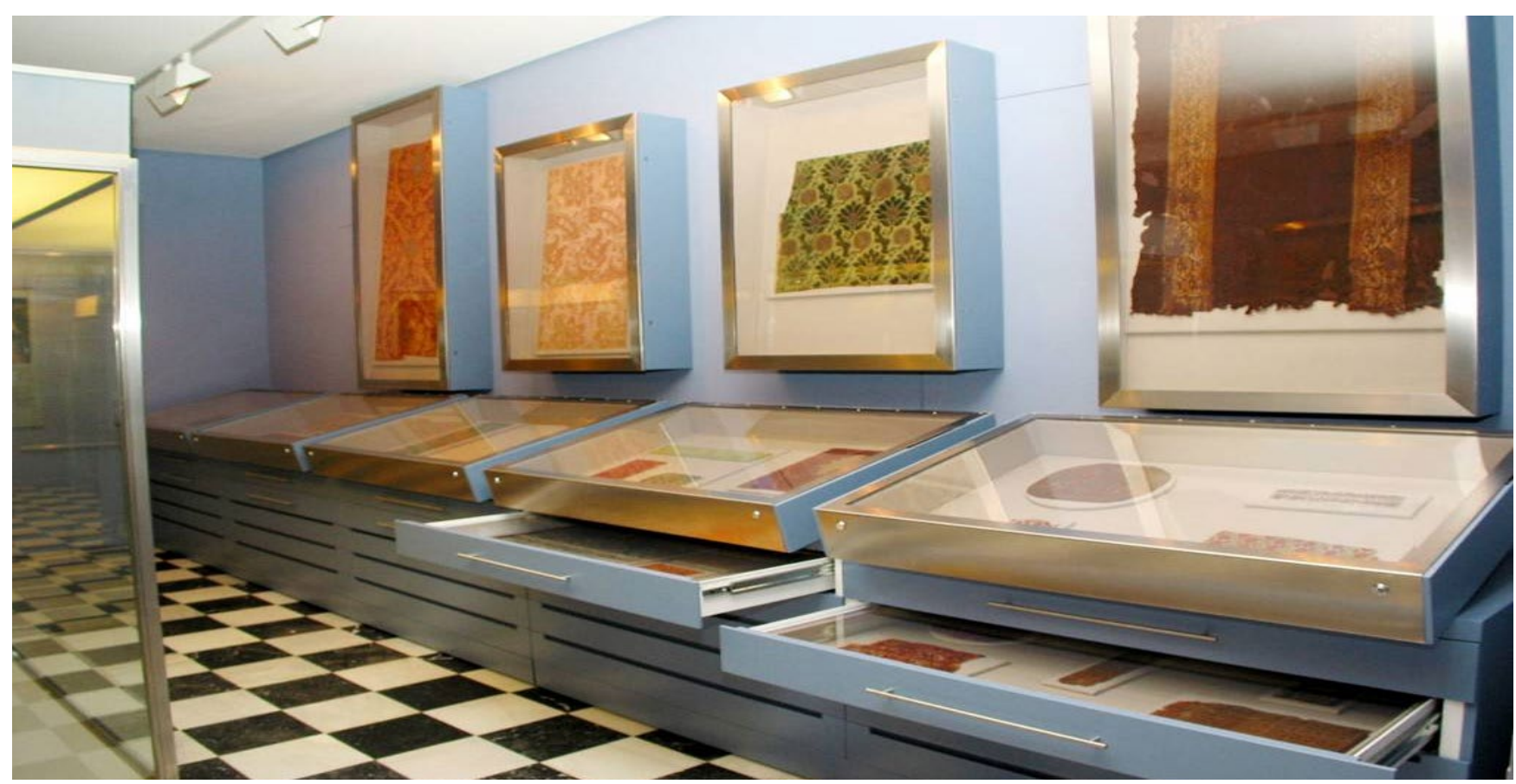

Figura 12.- Sala de tejidos de la planta segunda, remodelada en 2002-2003. @ MNAD 
El programa de exposiciones temporales da prioridad a las dedicadas al diseño contemporáneo, español y extranjero y a las relecturas de la colección [figuras 14 y 15]. Las que se basan en las relecturas de la colección, que hemos denominado "experimentales", investigan nuevos caminos en el modo de hacer una exposición temporal. Así se abordó la exposición "Fascinados por Oriente", inaugurada a finales de 2009 [figura 16].

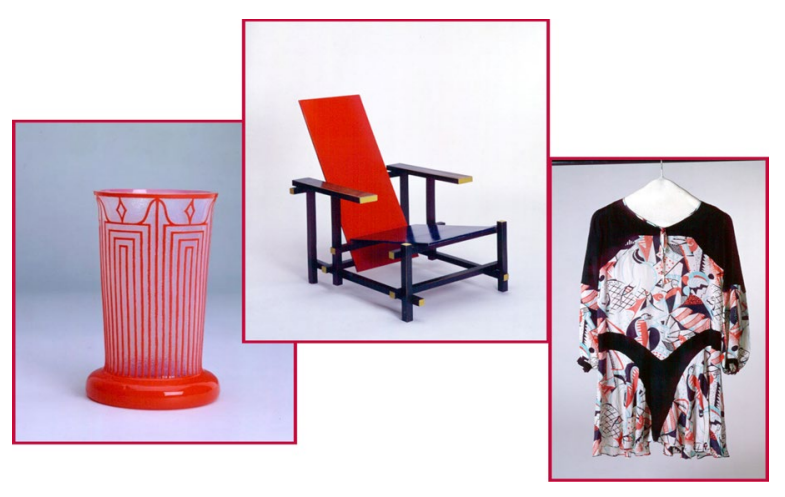

Figura 13.- Objetos de la colección de vanguardia. @ MNAD

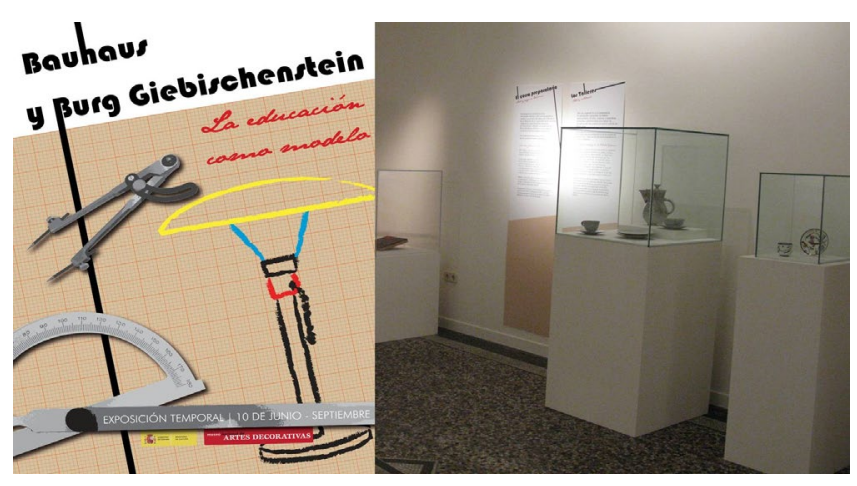

Figura 14. Exposición "Bauhaus y Burg Giebichenstein" 2011. ๑ MNAD

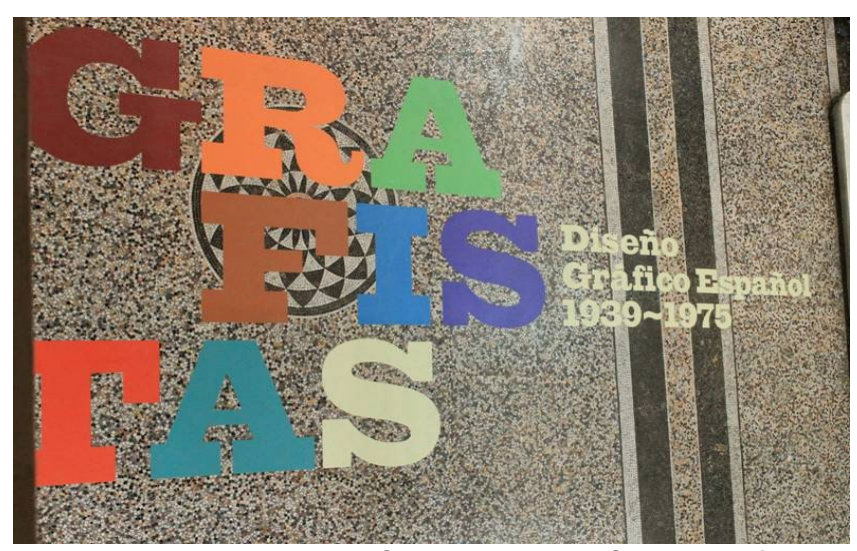

Figura 15.- Exposición "Grafistas: Diseño Gráfico Español 19391975". @ MNAD

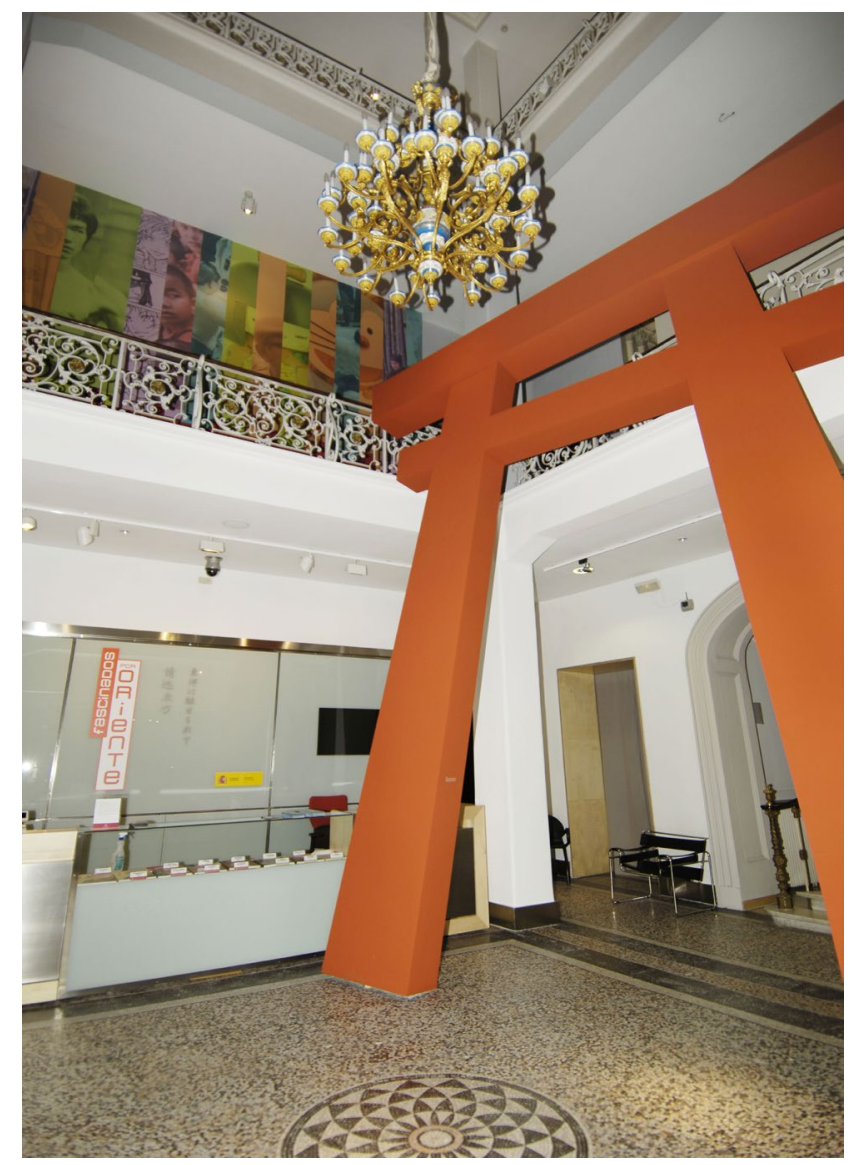

Figura 16.- Exposición “Fascinados por oriente", 2009-2010. ㄷ MNAD

-Siguen la metodología de la "exposición comunicativa"12, que incorpora al público como cocreador, merced a la realización de estudios que comprenden las evaluaciones previas, formativa $y$ sumativa; a través de ellas, los visitantes reales y potenciales contribuyen a conformar los objetivos del proyecto y el proyecto mismo, y a dar legiblidad al discurso, a la información y a la museografía.

—Utilizan el modelo de "comisariado colaborativo" o crowd curating, en el que el comisariado lo ejerce un equipo, que incluye técnicos del museo y agentes externos.

-Producen el modelo de "catálogo-historia", que no es un catálogo al uso, sino una narración sobre la exposición y que no precisa ruedas para su transporte. Es también un medio comunicativo de transmisión.

\section{La responsabilidad social en el museo}

La exposición "Diseño contra la pobreza" [figura 17], inaugurada en otoño de 2010, supuso un paso más, un punto de inflexión en la evolución de la institución, acercándonos a los modelos de "museo foro" y "museomedia"13. El proyecto implicó a instituciones públicas 


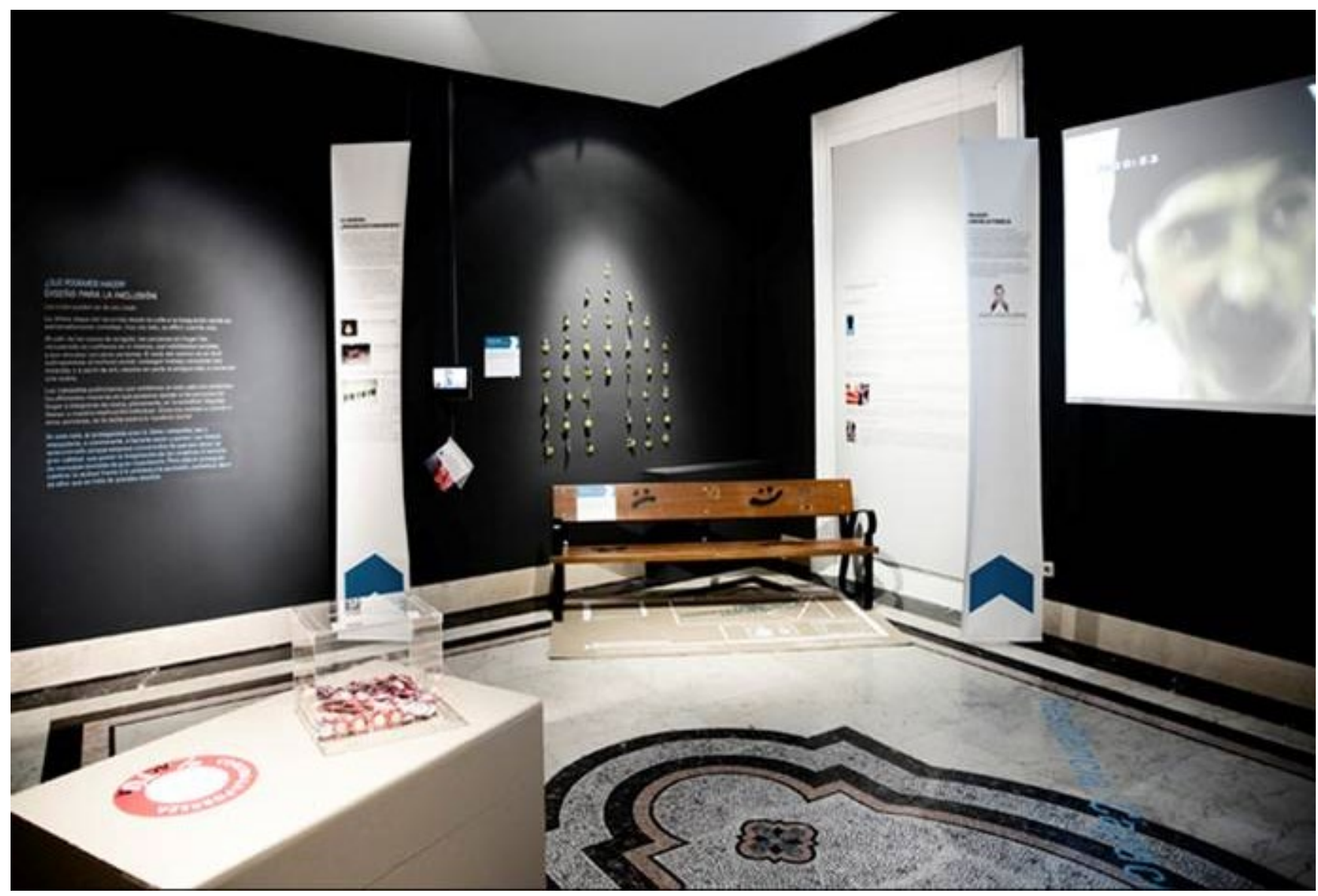

Figura 17.- La segunda exposición del proyecto “Diseño contra la pobreza”, 2010-2011. @ MNAD

y privadas y se materializó en un concurso de ideas y dos exposiciones temporales en el Museo. Fue un proyecto complejo y largo, fruto de la colaboración, en pie de igualdad, de diversos agentes, entre los que se contaban: los Ministerios de Cultura y de Sanidad, el sector del diseño profesional (DIMAD), algunas ONGs dedicadas a la atención de personas sin hogar y un grupo de personas sin hogar, a las que se entrevistó y aportaron sus historias y sus objetos para construir la Exposición.

Una metodología similar se está aplicando para la renovación de la colección permanente, abordada por un grupo de trabajo ad hoc. Por el momento se ha realizado una evaluación preliminar con el público real y potencial de la institución, y se pretende recurrir a la contribución de sectores profesionales de interés - del diseño, de la comunicación, de la pedagogía, de la empresa- y a estudiantes del área conceptual que abarca el museo, utilizando metodologías innovadoras como el panel delphi, los focus groups y los escenarios de futuro.

A partir de estas experiencias, se ha ido configurando una línea de actuación de marcado compromiso con los sectores de la población excluidos por diversas causas. Un hito importante fue el proyecto y la subsiguiente exposición "Enganchados al arte. Mi techo, mi espacio íntimo, mi hogar..." [figura 18], un proyecto en colaboración con el Centro Abierto Casa de Campo de Cruz Roja, en el que hemos trabajado con los drogodependientes usuarios del centro y la arteterapeuta Elena González. Seguirán otros del mismo tenor.

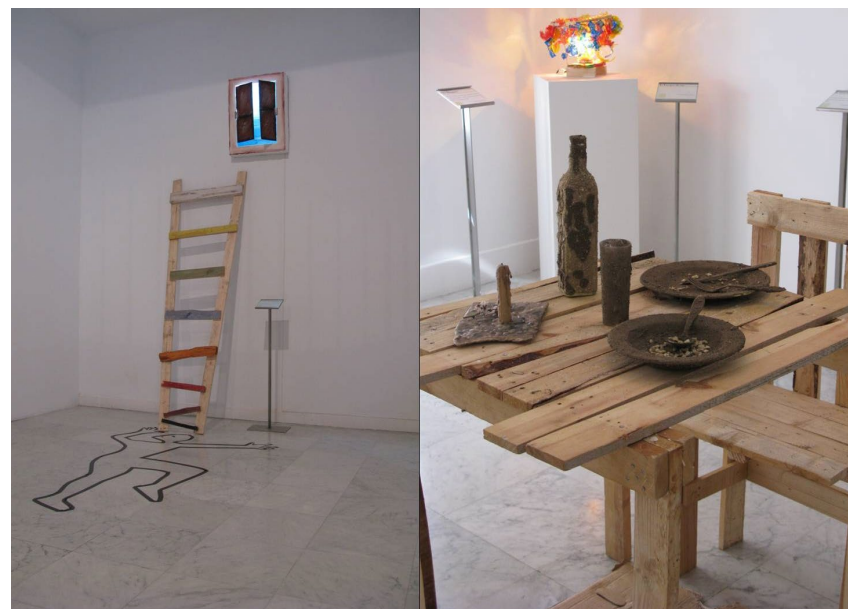

Figura 18.- Exposición "Mi casa, mi espacio íntimo, mi hogar", dentro del proyecto "Enganchados al arte", 2012. ๑ MNAD 
El compromiso con la formación ha dado lugar al programa "Diseño y pedagogía", que ofrece el museo como material de trabajo para que adolescentes y jóvenes elaboren respuestas a problemas concretos de creación y producción ${ }^{14}$, en el marco de proyectos de curso de Bachillerato, de Formación Profesional o de educación universitaria. Al finalizar los proyectos, cada colectivo ha culminado el trabajo con una exposición temporal en el museo.

Los productos culturales del MNAD evolucionan progresivamente desde la transmisión de saberes al fomento de acciones creativas que permitan a todos los tipos de público construir sus propios conocimientos. Se trata, finalmente, de dar a luz un museo comunicativo. A ello ha contribuido no poco la adopción de la dinámica colaborativa, es decir, del sistema de trabajo modular o por proyectos, que coexiste con el funcional: los departamentos cumplen con las tareas ordinarias, perolas de mayor envergadura, sobre las que pivota la identidad del Museo, son desarrolladas por equipos interdisciplinares, en los que a menudo participan especialistas externos y otras Instituciones.

Para concluir, hemos de reconocer que todos los museos- a través tanto de sus exposiciones, permanente y temporales- como de sus productos culturales-han interpretado sus colecciones desde la ideología y los valores coetáneos.

El MNAD ha reflejado en su evolución el desarrollo de las profesiones dedicadas a los objetos de consumo. En sus inicios como Museo Nacional de Arte Industrial se centró, aunque un poco tardíamente, en el fomento de los productos de la segunda Revolución Industrial y en una pedagogía avanzada, pero acabó por perder la batalla de la modernidad, rindiéndose al acopio de "obras de alto valor decorativo", sobre todo cuando, tras la Guerra Civil, el franquismo lo utilizó para consagrar una imagen triunfal de lo español.

Hoy nos enfrentamos al reto de poner el Museo al servicio de los intereses y expectativas de un público amplio, inmerso en una crisis socioeconómica, en un momento en el que la sostenibilidad, la interculturalidad y la solidaridad son los valores sobre los que se podría construir un futuro mejor. En ello, y en saber un poco más sobre nosotros mismos y nuestro pasado, está empeñado el MNAD.

Si finalmente nos llamamos o no Museo de Artes y Diseño, es todavía una incógnita. El Ministerio de Educación, Cultura y Deporte y los expertos, diseñadores, artesanos, estudiantes y el resto de nuestros aliados tendrán mucho que decir al respecto. Creemos que la pervivencia del Museo está justificada en tanto que permita a la sociedad participar e intervenir activamente en su construcción.

\section{Notas}

[1] La historia del MNAD ha sido objeto de varios estudios recientes, a los que este texto debe mucho de su contenido: CABRERA LAFUENTE, A y VILLALBA SALVADOR, M. "El Museo Nacional de Artes Decorativas (Madrid): de Museo Industrial a Museo Nacional de Artes Industriales (1850-1912). Antecedentes para la Historia del Museo", en Revista de Museología, no 30-31, pp. 81-88, y 36, 2006, pp. 117-123; CABRERA LAFUENTE, A y VILLALBA SALVADOR, M. “EI MNAD hace historia (I). Hace casi 100 años... el Museo Nacional de Artes Industriales", Estrado (boletín digital del MNAD), n³, 2008, p. 27; SÁEZ LARA, F. “EI MNAD hace historia (II y III). De los orígenes a la perspectiva actual: evolución conceptual", Estrado (boletín digital del MNAD), n 4, 2009, p. 56; y $n^{\circ} 5,2009$, p. 41.

[2] Lo mismo sucedió con el resto de los fabricantes que recibieron premios en los certámenes celebrados más allá de los Pirineos, como la firma Malvehy de sederos barceloneses especializados en brocados y brocateles, la platería Meneses y tantos otros.

[3] Museo Nacional de Artes Industriales. Anuario de MCMXVI, pp. 3 у 9.

[4] Decreto fundacional, 30 de diciembre de 1912.

[5] Anuario, op. cit, p. 9.

[6] Revista Nacional de Educación, Madrid, n . 2 1941; pp. 87-90.

[7] El traslado no fue inmediato: en 1933 todavía se anunciaba el museo en $A B C$ en su antiguo domicilio de la calle Sacramento.

[8] Anuario, op. cit., p. 10.

[9] Revista Nacional de Educación, op. cit., p. 89.

[10] Entrevista en ABC, 24 de enero de 1967, p. 63.

[11] La Vanguardia Española, 30 de noviembre de 1972, p. 8.

[12] Concepto desarrollado por Ángela García Blanco en su extensa bibliografía.

[13] CABALLERO GARCíA, L. y CASTILLO, R. "Diseño contra la pobreza: la sociedad civil como emisor", Museos.es: Revista de la Subdirección General de Museos Estatales, n 7-8, 2011-2012, p. 408.

[14] Con la Escuela de Arte 10 de la Comunidad de Madrid, de diseño gráfico, se abordó Fantasy Design en el marco de un proyecto europeo; con la Escuela 12, de diseño industrial, el proyecto Memoria $1+2$, cuya tercera convocatoria está en curso al redactar estas líneas; con el Istituto Europeo di Design, el proyecto de renovación de la identidad corporativa del museo y los trabajos del Máster de diseño textil de superficies; con la Universidad Europea de Madrid el diseño de la página web, también en curso. 


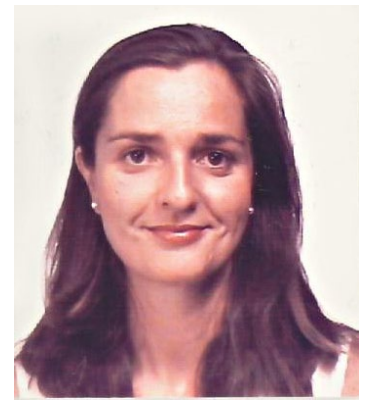

\section{Paloma Muñoz-Campos}

Museo Nacional de Artes Decorativas. Madrid

paloma.munozcampos@mecd.es

Coordinadora de proyectos y responsabilidad social del MNAD. Licenciada en Historia del Arte (UAM) y Diplomada en ConservaciónRestauración (ECRBC) de Madrid, es restauradora de plantilla en el Museo desde 1992. Pertenece al Cuerpo Facultativo de Conservadores de Museos desde 2005, habiendo ejercido como Jefe de Conservación y como Subdirectora en el MNAD. Ha pronunciado conferencias y publicado textos sobre prevención, almacenamiento y exposición de Bienes Culturales.

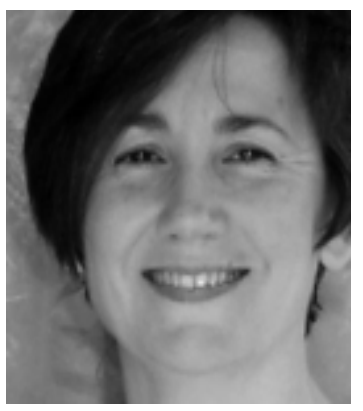

\section{Sofía Rodríguez Bernis}

Museo Nacional de Artes Decorativas

sofia.rodriguez@mecd.es

Directora del Museo Nacional de Artes Decorativas, ha trabajado en los museos del Prado, Reina Sofía y del Ejército. Se ha ocupado de la historia del mueble histórico y de los interiores en la Edad Moderna. Ha publicado numerosos artículos sobre estas materias y textos sobre museología. Ha comisariado distintas Exposiciones como "el Quijote en sus trajes". 